ISSN 2072-4292

www.mdpi.com/journal/remotesensing

Article

\title{
GIS-Based Roughness Derivation for Flood Simulations: A Comparison of Orthophotos, LiDAR and Crowdsourced Geodata
}

\author{
Helen Dorn ${ }^{1}$, Michael Vetter ${ }^{2,3}$ and Bernhard Höfle ${ }^{1, *}$ \\ 1 Institute of Geography \& Heidelberg Center for the Environment (HCE), Heidelberg University, \\ Berliner Str. 48, D-69120 Heidelberg, Germany; E-Mail: Helen.Dorn@geog.uni-heidelberg.de \\ 2 Institute of Geography, University of Innsbruck, Innrain 52f, A-6020 Innsbruck, Austria; \\ E-Mail: michael.vetter@uibk.ac.at \\ 3 Centre for Water Resource Systems; Research Groups Photogrammetry \& Remote Sensing, \\ Vienna University of Technology, Karlsplatz 13, A-1040 Vienna, Austria \\ * Author to whom correspondence should be addressed; E-Mail: hoefle@uni-heidelberg.de; \\ Tel.: +49-6221-54-5594; Fax: +49-6221-54-4529.
}

Received: 4 October 2013; in revised form: 28 January 2014 / Accepted: 12 February 2014 / Published: 24 February 2014

\begin{abstract}
Natural disasters like floods are a worldwide phenomenon and a serious threat to mankind. Flood simulations are applications of disaster control, which are used for the development of appropriate flood protection. Adequate simulations require not only the geometry but also the roughness of the Earth's surface, as well as the roughness of the objects hereon. Usually, the floodplain roughness is based on land use/land cover maps derived from orthophotos. This study analyses the applicability of roughness map derivation approaches for flood simulations based on different datasets: orthophotos, LiDAR data, official land use data, OpenStreetMap data and CORINE Land Cover data. Object-based image analysis is applied to orthophotos and LiDAR raster data in order to generate land cover maps, which enable a roughness parameterization. The vertical vegetation structure within the LiDAR point cloud is used to derive an additional floodplain roughness map. Further roughness maps are derived from official land use data, OpenStreetMap and CORINE Land Cover datasets. Six different flood simulations are applied based on one elevation data but with the different roughness maps. The results of the hydrodynamic-numerical models include information on flow velocity and water depth from which the additional attribute flood intensity is calculated of. The results based on roughness maps derived from
\end{abstract}


LiDAR data and OpenStreetMap data are comparable, whereas the results of the other datasets differ significantly.

Keywords: hydraulic modeling; land use/land cover classification; OpenStreetMap; ALS point cloud; floodplain; vertical vegetation structure; Volunteered Geographic Information; hydraulic friction coefficient

\section{Introduction}

Floods are natural disasters that are present all over the world. In recent years, their number has been increasing due to changes in land use and climate amongst others [1,2]. People are still settling in danger areas but in some cases they are forced to live there because of a worldwide increase of population over the last decades. Hence, the number of people affected by natural disasters has continuously been increasing [1].

In 2005 a major flood event took place in central Europe. In Austria the western part was strongly affected by this flood. In the Bregenzer Wald (Austria, Vorarlberg), the highest precipitation rate and discharge, since starting the measurements, was registered. An occluded front was the reason for heavy precipitation, which led to flooding in the whole region. In Vorarlberg, the severe flood claimed two lives and caused 178.2 million Euros of damage $[3,4]$.

This incident shows that floods count to natural disasters with an increasing number [1]. The probability of flooding, as well as the vulnerability and the potential damage for each area, is an important part of risk prevention [2]. Hydrodynamic-numerical (HN-) models can be used to predict potential inundation areas [5] by computing flood risk and hence reduce "economic damage and human suffering" [6]. Therefore, the available data base plays an important role, because high quality of geographic data, especially regarding spatial resolution, is essential for reliable flood simulations. LiDAR and satellite data in combination with geographic information systems constantly improve the technical preconditions [2].

The roughness of the Earth's surface (e.g., roads, ground) and the objects hereon (e.g., buildings, vegetation) in terms of hydrodynamic friction are an essential input for flood simulations. This study aims at an analysis of roughness parameterization from different data sources. Roughness maps are derived from orthophotos, airborne LiDAR data, official land use data, CORINE Land Cover (CLC) data and crowdsourced OpenStreetMap (OSM) data. The main objective of the paper is the comparison of different roughness maps via an analysis of the effects of the diverse input layers on the flood simulation results to obtain an estimate for fitness-for-use. In this study the roughness parameter for the hydrodynamic simulation is defined through the Manning's formula and based on literature. A land use/land cover classification (LULC) is part of the roughness derivation. This paper investigates river flooding in a study area in the Alps of Western Austria. 


\section{Related Work}

\subsection{Flood Simulation}

The prediction of natural disasters like floods is an essential part of disaster control [7]. Flood simulations are research tools to predict inundation areas and flood situations. Using this prediction results, recommendations of proper protection measures can be given [8]. Input data for 2D HN-models are as follows: geometry, roughness information and boundary conditions (e.g., discharge, water level) [9].

Two-dimensional HN-models are used to calculate flood parameters for the watercourse and the floodplain. Relevant parameters are water depth, inundation area and flow velocity [10]. Amongst other possibilities the results are used to calculate risk maps or to optimize river and lake regulation $[11,12]$.

Computer-assisted flood simulations are carried out as 1D, 2D or 3D HN-models [5,10]. One-dimensional flood simulations deliver results on a regional scale and with a short computation time. In contrast, 2D HN-models are primarily used on a local scale and need a longer computation time of up to several days [10]. Three-dimensional HN-models are required for detailed analysis on a small scale [13]. In addition, 1D and 2D HN-models can be combined to complement each other with regard to computation time and high resolution (see [10]).

Floodplain and objects hereon have a strong influence on the water flow [14]. Hence, floodplain roughness is an important flood parameter for river flow HN-modeling. The roughness values used by the HN-Model are mostly based on LULC classes, where a specific roughness value is added to one class. In practice, the roughness parameter is often used for model calibration. The roughness values of the different LULC classes are changed until the model results fit observations. Straatsma and Baptist [5] criticize this approach because the used values do not represent the physical conditions and cannot compensate for example shortcomings in the model. According to their opinion roughness values have to be accurately estimated to reduce variation of input parameters during calibration. They argue that in common practice discharges which do not fit reality are used and so the modeling results cannot fit observations [5].

Calibration of $\mathrm{HN}$-models is commonly performed using given roughness parameter values which are derived through LULC data [15]. This method is also criticized because land use and land cover constantly change and static values can lead to unsatisfactory simulation results [16]. Yet, roughness parameters like Manning's $n$ estimated through a lookup table are successfully applied to HN-models [17]. There are various authors who offer Manning's $n$ lookup tables for channels and floodplains, e.g., Chow [14] or Arcement and Schneider [18].

Besides roughness, geometry is an important input for $\mathrm{HN}$-modeling. Especially the riverbed geometry has to be processed as accurate as possible. For a discharge which leads to flood (e.g., HQ100), the floodplain has also to be taken into account [19]. For the HN-model geometry can be represented as a computational grid, the so-called mesh or as rasterized data (regular grid). The mesh consists of triangular cells which vary in size. For each cell quantities are calculated such as water depth or flow velocity [10]. HN-simulation software is often not able to process a large amount of data. Hence, Mandlburger [19] developed an algorithm for reducing data volume in different zones (river bed, floodplain, etc.). In this way, highly detailed topographic data in the mesh is compressed while relevant data is preserved. 


\subsection{Hydraulic Roughness Coefficient}

It is necessary for hydrodynamic-numerical modeling to parameterize roughness through a friction coefficient like Manning's $n$ [14] or Chézy's $C$ [5], which are empirical values. A common approach in order to derive floodplain roughness focuses on the generation of LULC classes based on remote sensing data with roughness values from a lookup table. Another approach is to use one single roughness value for the whole floodplain area [6,20]. Vegetation and other objects on the Earth's surface have strong influence on the flow [7]. Accordingly, roughness and its derivation is an important factor in $\mathrm{HN}$-modeling.

Straatsma and Baptist [5] developed a repeatable method for an automated derivation of roughness from multispectral and airborne LiDAR (ALS) data. In HN-modeling, near surface vegetation has the largest impact on the flow of water [9]. Therefore, Straatsma and Baptist analyze height and density of vegetation by using ALS data. This approach leads to a high-resolution roughness map [5]. Another study concerning friction parameterization from ALS data for 2D HN-modeling focuses on the height of vegetation in rural areas and uses a spatiotemporally varying friction factor [21].

In [9] they estimate hydraulic roughness from a 3D ALS point cloud by using a voxel data structure. In their approach voxels are 3D bounding boxes, with defined length, width and height. Point cloud echoes are sorted into cells and then into voxels by their normalized height above ground. They assign roughness values according to Manning's equation based on literature [9].

\subsection{Risk Estimation}

Damages due to natural disasters have increased over the years. Catastrophes are-besides the natural phenomenon - attributable to political, social and economic factors [22]. Moreover, natural disasters always have economic damage and strong influence on mankind. Accordingly, it is important to prevent damage for example by building appropriate protection measures.

The estimation of potential flood damage strongly depends on the water depths of the river and inundation areas which are computed by HN-models. Further information like contamination can be considered for detailed damage estimation on a local scale [23]. There is a distinction between direct and indirect damage. On the one hand, direct damage is related to the flood itself, while indirect damage occurs spatially and temporally outside the main incidence. Furthermore, there is tangible and intangible damage. The first is monetarily valuable whereas the latter one is not. Hence, damage estimation concentrates on tangible damage [24,25]. Economic loss can also be subdivided into categories e.g., agriculture, industry or residential building (see [26]).

Apart from different damage categories, there are several flood risk estimation approaches on mesoscale and on microscale basis [27,28]. The "Schweizer Modell" [29] can be applied to simulation results for a first risk estimation. It subdivides the area in weak, moderate and high flood intensity according to water depth or product of water depth and flow velocity (see $[28,29]$ ). 


\section{Study Area and Datasets}

The aim of the study is to compare flood simulations based on different datasets. Official as well as freely available geodata is required for this purpose. The Federal State of Vorarlberg, Austria, provides different datasets which are suitable for HN-models.

\subsection{Study Area}

The study area has an extent of approximately $3 \mathrm{~km}^{2}$ and is located in the West of Austria (Vorarlberg) close to the river mouth of the Bregenzer Ache into Lake Constance (Figure 1). The Bregenzer Ache is about $80 \mathrm{~km}$ long and a reach with a length of $2.8 \mathrm{~km}$ is object of investigation in this study [30,31].

Figure 1. Location of the study site in the Austrian Alps at the Lake Constance.
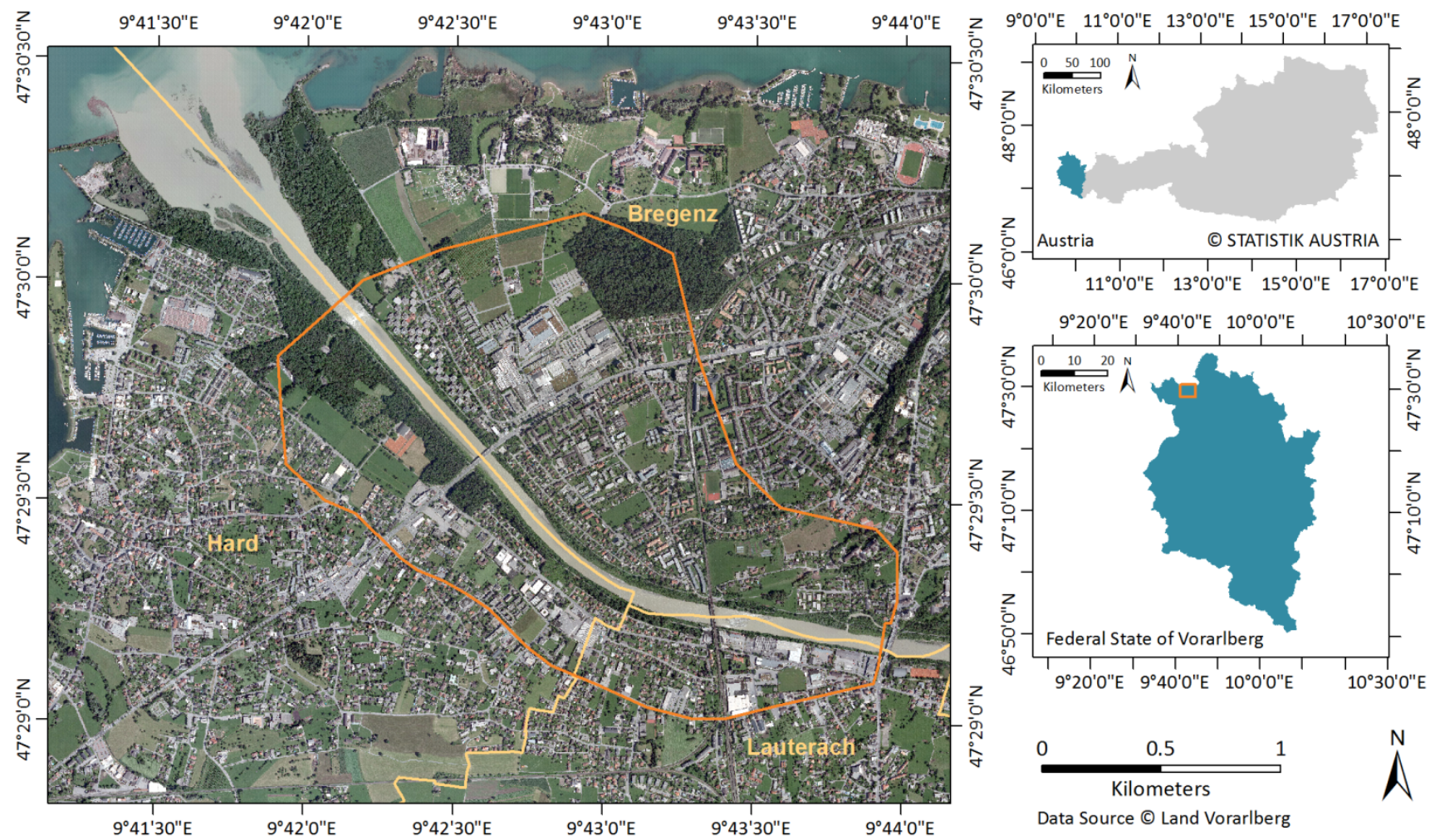

In the study area, the river is straightened to a width between $100 \mathrm{~m}$ and $110 \mathrm{~m}$. Until the middle of the 20th century, there had been some large-area gravel banks but only a few of them remained. Today, there is an artificial rock barrier to reduce sedimentation around the river mouth [32].

The closest gauging station in the study area is located near Kennelbach approximately $3 \mathrm{~km}$ upstream. A specific discharge which is statistically reached at least once every 100 years is also called HQ100 and actually lies at $1,450 \mathrm{~m}^{3} / \mathrm{s}$ for the gauging station in Kennelbach [31]. In this study a discharge of $1,391 \mathrm{~m}^{3} / \mathrm{s}$ is used for the $\mathrm{HN}$-model. This value is related to the highest registered discharge during the flood in 2005 with $1,350 \mathrm{~m}^{3} / \mathrm{s}$, which was the HQ100 until 2012. 


\subsection{Datasets}

There is several official data available for the study area. The Federal State of Vorarlberg provides orthophotos, airborne LiDAR data and land use data. Freely available geodata like CORINE Land Cover data and OSM data also plays an important role in this study (Table 1).

Table 1. Overview of data sources and datasets used as input for roughness map derivation and flood simulation.

\begin{tabular}{cccc}
\hline Data Source & Provider & Date & Dataset \\
\hline Orthophotos & Federal State of Vorarlberg & 2009 & TC and CIR image \\
LiDAR data & Federal State of Vorarlberg & 2003 & Point cloud, nDSM, signal intensity \\
Official land use data & Federal State of Vorarlberg & $2001 / 2002$ & Vector polygons \\
OpenStreetMap data (OSM) & OpenStreetMap contributors & 2013 & Vector polygons and polylines \\
CORINE Land Cover (CLC) & Environment Agency Austria & 2006 & Vector polygons \\
\hline
\end{tabular}

In this study the LULC classification is based on orthophotos which were orthorectified using an ALS elevation model. There are true color (TC) orthophotos and color near infrared (CIR) orthophotos taken by the Vexcel Ultracam Xp camera [33].

The ALS point cloud was captured by Topscan with an OPTECH ALTM 2050 System. The average point density is 2.3 points $/ \mathrm{m}^{2}$ and the average ground point density lies at 1.6 points $/ \mathrm{m}^{2}$. A digital surface model (DSM) and a digital terrain model (DTM) with a resolution of $1 \mathrm{~m}$ were derived from the original point cloud. Furthermore, an nDSM (normalized digital surface model) which contains all objects above the earth surface was calculated [34]. Besides the elevation data, signal intensity values are provided. The signal intensity values are uncorrected (see [35]) first- and last-pulse DIM's (digital intensity models). Not only LiDAR raster data (nDSM, DIM's) but also the original ALS point cloud is used for two separate roughness map derivations.

An official land use classification dataset based on orthophotos with additional data (e.g. network of roads) from 2001/2002 is also provided by the Federal State of Vorarlberg [36]. Eight classes are included in the dataset; five of them are within the study area and are used for the roughness parameterization.

The latest CLC data for the study area is from 2006. Five out of 44 CLC classes are relevant for this study [37]. In Austria, the data was generated on a scale of 1:100,000 based on satellite imagery.

Furthermore, OpenStreetMap (OSM) data is used as input for flood simulation. OSM provides open data; thus users are allowed to copy or to adapt data taking the "Open Database License (ODbl) v1.0" into consideration. It is one of the most popular Volunteered Geographic Information (VGI) projects and the common acceptance and significant increase of data shows the potential of crowdsourced data [38]. Therefore, OSM data is very up-to-date and investigations among the crowdsourced community reveal that a high number of contributors have an OSM-related background ensuring the quality [39].

\section{Methods}

Geometric information, roughness and a hydrograph are the main parameters in a hydrodynamic numerical model. This study focuses on the roughness parameter and the effects of the roughness 
layers on the flood simulation results. Geometry as well as roughness can be derived from LiDAR data. Orthophotos, official land use data, CLC and OSM data are used for further roughness map derivations.

Figure 2 shows the study's workflow. The first step is to extract a proper geometry dataset out of the provided ALS data similar to methods of Mandlburger et al. [8] and Vetter [40]. For each input dataset the related LULC classes are derived with different ways of proceeding. A Manning's $n$ value is added to each LULC class and combined with the mesh. A mesh is a triangular network of computational nodes with roughness information for each node. Together with boundary conditions (e.g., hydrograph) the mesh is an input to a hydrodynamic-numerical model with BASEMENT [12]. Finally, six different models are calculated based on one geometry mesh and the six different roughness maps. The results are depicted as water depth and flow velocity.

Figure 2. Workflow of GIS-based roughness derivation and comparison for flood simulations.

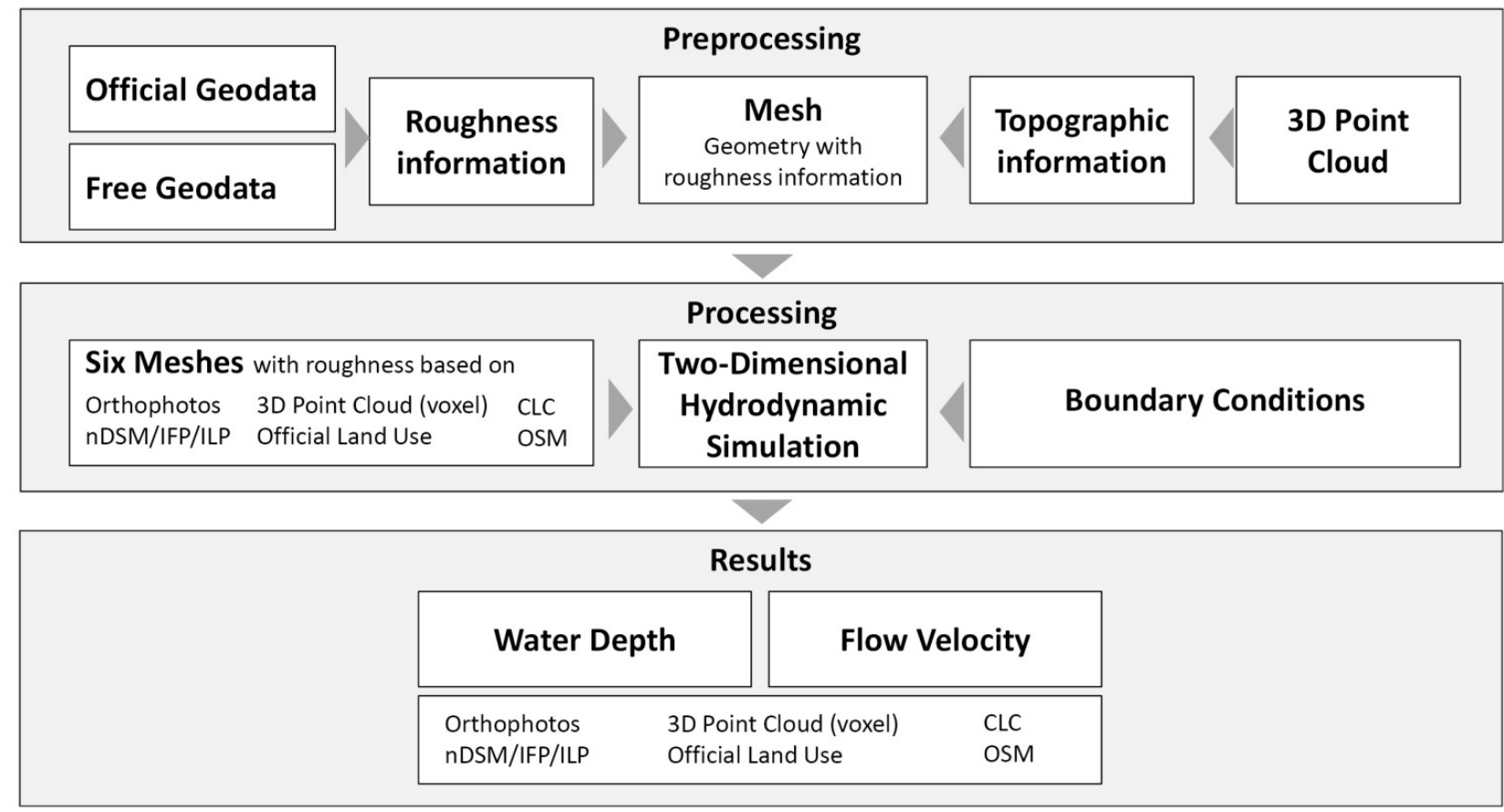

\subsection{Roughness Parameterization}

The roughness parameterization consists of different parts. On the one hand, there is the LULC classification defining the roughness classes, which is the focus of this study, and on the other hand, there is the friction parameter in the HN-model defined by Manning's n values.

Two LULC classifications are processed by a supervised classification method in order to gain applicable results. In this study, Feature Analyst (Overwatch) [41] is applied to orthophotos and ALS data. The study area determines the region of interest for the classification. Small areas below $30 \mathrm{~m}^{2}$ are aggregated. The calculated LULC classes can be improved separately, e.g., by adding missed features or removing clutter. Finally, the improved classes are combined to a LULC classification.

For the first classification, a true color orthophoto was used in combination with a color infrared orthophoto. The second classification using LiDAR data was based on nDSM and signal intensity data of first pulses/echoes (IFP) and last pulses/echoes (ILP). The river needed to be extracted separately with the feature type wide linear feature because the results of a combination with the other classes 
were not suitable. This has no effect on the flood simulations because exactly the same river has to be used in all roughness maps. An alternative method to derive the river based on LiDAR data is presented by [40].

An accuracy assessment helps to check automated feature extraction classification results. Fifty random samples with a width of $3 \times 3$ pixels were manually checked by using the input data sets of the classification. The results are the basis of an error matrix as well as a confusion matrix, which are used for the calculation of completeness, correctness [42] and kappa [43,44].

An additional way of proceeding with LiDAR data uses a voxel structure. This method developed by [9] is especially suitable for vegetation classes, which exhibit a specific vertical vegetation structure and extent. Therefore, laser echoes are counted in predefined cells; then the cells are aggregated to voxels and finally neighboring voxels are aggregated to connections, which are representing vertical connected vegetation structures. In this study, only the lowest connections (No. 1, surface near connection) are used [9] because they are most relevant for flood simulations. As mentioned before, the method is appropriate for vegetation classes such as forest, crop/grass and shrub. The vegetation classes are defined by the maximum height of the lowest connections and the relation of points per connection (pCon) to points per cell (pCell) (Table 2).

Table 2. Definition of vegetation classes in the voxel approach.

\begin{tabular}{ccc}
\hline Class & Max. Height (Con. no. 1) & Threshold on pCon/pCell \\
\hline Crop/Grass & $\leq 0.25 \mathrm{~m}$ & \\
Shrub & $>0.25 \mathrm{~m}$ and $<5 \mathrm{~m}$ & $\leq 0.75$ \\
Forest & $\geq 5 \mathrm{~m}$ & $\geq 0.75$ \\
\hline
\end{tabular}

The road class is extracted using low signal intensity values and nDSM height below $0.5 \mathrm{~m}$. The building class is based on OSM buildings because it is not possible to extract this class using the voxel approach. Since the same river is needed in every roughness map for comparing the simulation results, the Bregenzer Ache is classified by a supervised classification based on orthophotos.

Additional official land use data is provided by the federal state Vorarlberg. It is used for a further roughness parameterization, in which the data does not need further editing. Roughness layer and mesh are directly combined for the flood simulation.

The OSM data has to be prepared. Linear features (river, roads, railways) are buffered with adequate width to generate areal information, while buildings and natural structures are available as polygons. Railways are considered as a part of the road class for the simulation. Some land cover classes are merged to meaningful and comparable classes (farmland, grass, meadow and orchard to crop/grass). There is no information about any shrub, so in this case the class has to be dropped. However, the class "forest" exists in OSM data. In the housing areas, there are many data gaps. Shrubs, single trees, gardens and some agricultural area or meadows are not edited. Thus, a "no data" class with a defined roughness value (0.03; see Table 3$)$ is required for the OSM roughness layer.In contrast, CLC data for the study area is complete but with a coarse resolution. The roughness classes result from the CLC nomenclature. There are no single buildings or roads but "discontinuous urban fabric" and "industrial or commercial units". These classes are combined in the road class. Gardens, shrubs and other objects are missing; therefore the roughness value for roads is more appropriate than 
the building value. The CLC category "agricultural areas" is suitable for the crop/grass class and also forest areas are listed. To conclude, three out of five target classes are provided besides the river.

The described LULC classifications as a part of the roughness derivation are prepared for a combination of roughness and geometry. Thereafter, HN-models can be processed.

\subsection{Hydrodynamic-Numerical Modeling}

Two-dimensional HN-models generate information about flood waves, maximal inundation depth, inundation areas and the reflow of flood waves [45]. Therefore, differential equations are solved to simulate the flow of water. In this study, the software BASEMENT is used to solve the shallow water equation by using a cell-centered finite volume method in combination with a Riemann solver. In BASEMENT an unstructured mesh of the floodplain and a dense hydraulic mesh of the river bed which represents the geometry in the study area are used as in many other HN-models. The terrain height and the roughness parameter are defined at each mesh vertex (see $[8,12,46,47])$.

The mesh is generated with a method developed by Mandlburger [19] and based on ALS DTM with $1 \mathrm{~m}$ resolution. It consists of inner angles with 20-140 degree. In the channel area a hydraulic grid with edge length $14 \mathrm{~m}$ to $3 \mathrm{~m}$ is used. Further, existing flood protection — dykes on both river sides and temporary concrete elements on top-is included. Due to the fact that the vertex distance correlates with the slope and therefore it is large in plane areas and small in steep areas. The maximal area of a triangle is $75 \mathrm{~m}^{2}$. Thereafter, the mean height difference between final mesh and DTM is $15 \mathrm{~cm}$ and has a median with $9 \mathrm{~cm}$. The bridge in the middle of the study area acts as a flow barrier, where a log jam is included in the model.

In addition to geometry, friction is an important simulation parameter. A popular empirical equation for open channel flow is the Manning Equation (1) [17]. The Manning roughness values in this study are based on the today well-known form in metric units [14]:

$$
\begin{gathered}
V=\frac{1}{n} \times R^{\frac{2}{3}} \times S^{\frac{1}{2}} \\
V=\text { mean flow velocity }\left[\frac{\mathrm{m}}{\mathrm{s}}\right] \\
R=\text { hydraulic radius }[\mathrm{m}] \\
S=\text { slope }\left[\frac{\mathrm{m}}{\mathrm{m}}\right] \\
n=\text { Manning's roughness coefficient }
\end{gathered}
$$

The roughness value lookup table of this study is based on the values provided by [14], except the building class (Table 3, [14,48]).

There are several possibilities to include buildings in flood simulations. Usually, buildings are blocked out or their roughness value is increased. Syme [48] compares both approaches. However, in the block out simulation scenario water cannot enter buildings or underground parking lots. Yet, there are some underground parking lots near the river and therefore the simulation will gain more realistic results with a higher roughness value for buildings. According to Syme a Manning's $n$ value of 0.4 is appropriate [48]. 
Table 3. Manning's $n$ values according to Chow [14]. The value of the building class is provided by Syme [48].

\begin{tabular}{ccc}
\hline LULC Class & Manning's $\boldsymbol{n}$ Values & LULC ID \\
\hline Building & 0.4 & 1 \\
Forest & 0.15 & 3 \\
Shrub & 0.1 & 2 \\
River & 0.05 & 5 \\
Road & 0.016 & 4 \\
Crop/grass & 0.035 & 7 \\
No data & 0.03 & 6 \\
\hline
\end{tabular}

As mentioned before, the river is equal in all roughness maps. Furthermore, the river is buffered with $3 \mathrm{~m}$ distance in order to ensure a homogenous area for the simulation. Each LULC class has a unique LULC ID which is added to the mesh. In this way, every vertex has defined topographic and roughness information. The specific Manning's $n$ value is added during the simulation in BASEMENT. Further input data for the 2D HN-models are boundary conditions (e.g., discharge data). Therefore, a test discharge with $1,391 \mathrm{~m}^{3} / \mathrm{s}$ is applied to the model. The calibration of the HN-model is based on Manning's $n$ values extracted from literature. The Manning's $n$ values are changed, within the range of values of each LULC class presented in literature, until the extent of the inundated area of the 2005 event is reached. The resulting Manning's $n$ value for each LULC class is finally assigned to the different roughness maps. After the calibration, the newly installed flood protection measures are integrated into the topographic data. This modified LiDAR topographic information is finally used for the HN-model.

\subsection{Risk Estimation}

Additional data on vulnerable objects is required to give detailed flood damage estimation on microscale especially for buildings. The aim of the study is to compare simulation models on the basis of different roughness maps. A straightforward approach based on three flood intensity classes is applied to water depth data. In this way, it is possible to gain overview information about risk in residential areas. This leads to a flood intensity map with three classes: weak, moderate and high flood intensity or risk classified by water depth (Table 4). Additionally, buildings which are affected by the flood with certain flood intensity are determined. For this purpose, OSM buildings are used and combined with the different flood simulation results.

Table 4. Risk Estimation: Used flood intensity classes according to [28,29].

\begin{tabular}{cc}
\hline Flood Intensity & Water Depth h $(\mathbf{m})$ \\
\hline I (weak) & $<0.5$ \\
II (moderate) & $0.5 \leq \mathrm{h} \leq 2.0$ \\
III (high) & $>2.0$ \\
\hline
\end{tabular}




\section{Results and Discussion}

The results of this study are divided into two parts. The first one displays the differences of the roughness maps included in the hydrodynamic model. The second part illustrates the results of the hydrodynamic simulations for inundation area, water depth and flood intensity. The flood intensity is used to gain more detailed information about the simulation results.

\subsection{Roughness Maps}

The roughness maps with up to six roughness classes are depicted in Figure 3. The maps based on official data (Figure 3a-d) are more detailed than the ones with freely available data (Figure 3e,f).

The object-based image analysis for LULC classification with Feature Analyst achieves suitable results as reflected in the accuracy assessment. The results of the accuracy assessment are listed in Table 5 and reveal a high kappa in both classifications (based on LiDAR data or orthophotos). Further, overall and average accuracy show a high percentage. Accordingly, the orthophoto classification has only little advantage but the significance of numbers should not be overestimated because all calculations are based on random samples.

The single classes indicate more significant differences. In particular the shrub class in the ALS raster data classification reaches only a correctness of $50.44 \%$. This is also visible in the LULC map (Figure $3 b$ ). Hence, this class is not sufficiently classified by Feature Analyst with nDSM and signal intensity data. Better results may be gained in combination with orthophotos.

A map derived from orthophotos reveals difficulties with flat roofs because they have similar spectral characteristics like roads. A combination of both data types could lead to an improvement (see [49]). In this study, however, a combination was not applied for two reasons. First, there are six years in between the reference years $(2003,2009)$. Second, the aim of the study is to compare different datasets and their suitability for hydrodynamic simulations instead of a combination of datasets.

The roughness of the river bank area is important, especially during floods. There grows a lot of shrub which has theoretically a significant effect to the flow regime during floods. The shrub class is more distinctive in the orthophoto roughness map (Figure 3a) than in the one based on $\mathrm{nDSM} /$ signal intensity (Figure 3b). Vetter [50] suggests a combination of nDSM/signal intensity with the voxel approach to gain an improvement of the classified shrub. The anthropogenic classes (building, road) indicate low to moderate accuracies for both classifications (Table 5) but they are sufficiently classified for the hydrodynamic simulations.

The voxel approach (Figure 3c) mainly focuses on vegetation classes; therefore, vegetation is well extracted. There is a forest next to the river in the western part of the study area. In comparison to the other roughness maps, a lot of shrub is classified within the forest, which also applies to the forest in the north eastern part. This is the result of the voxel classification by height only using the surface near connection class. Hence, roughness parameterization with voxels leads to the largest shrub class. Additional data (ALS signal intensity, OSM) is required for the derivation of roads and buildings. 
Figure 3. LULC classifications based on (a) orthophotos; (b) nDSM, IFP, ILP; (c) voxel; (d) official land use data; (e) CLC data; (f) OSM data.
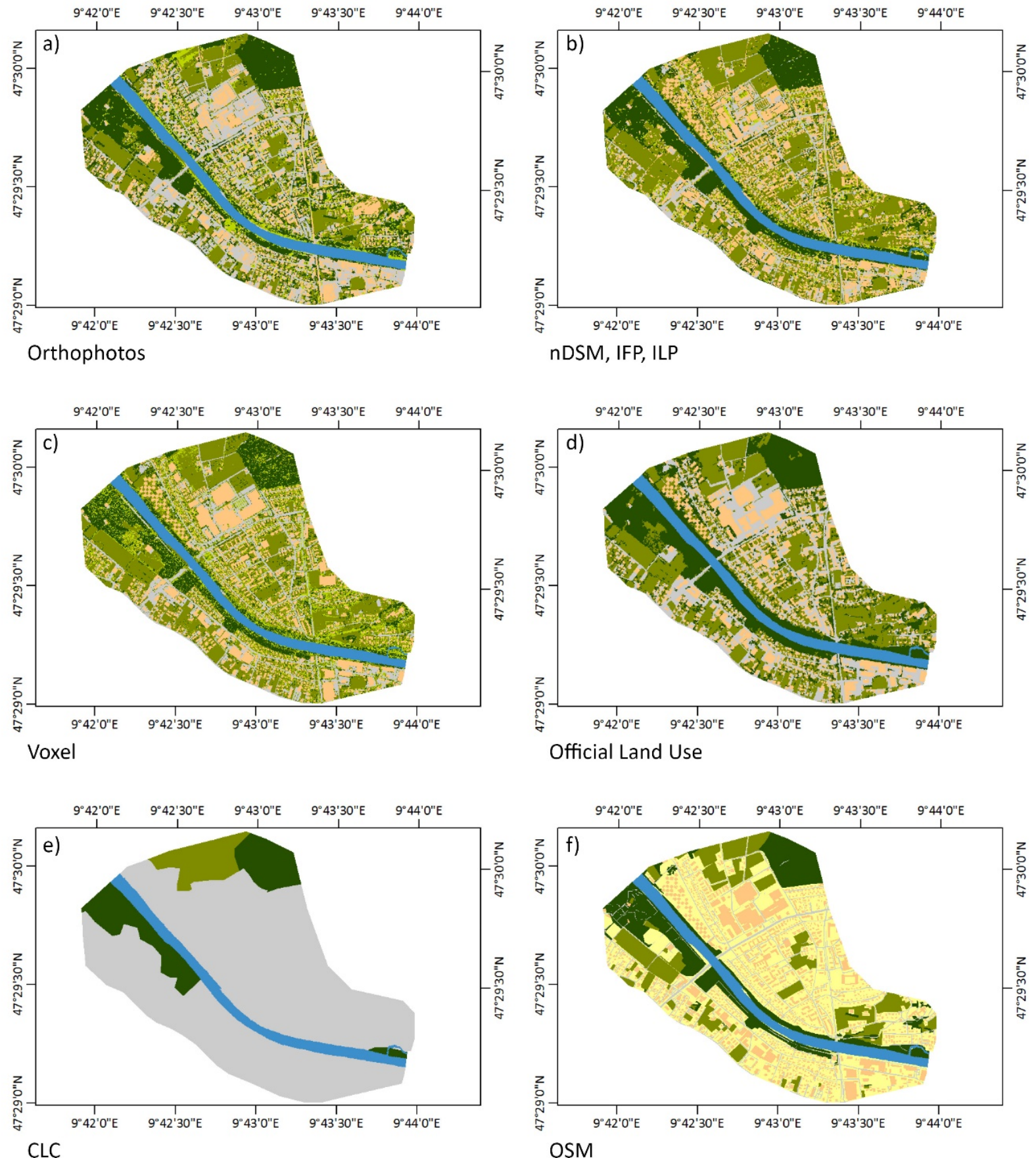

Land Use / Land Cover classes

\begin{tabular}{|ll|}
\hline Road & Crop/Grass \\
\hline Building & River \\
\hline Forest & No Data \\
\hline Shrub & \\
\hline
\end{tabular}

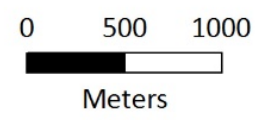

Orthophotos, LiDAR data, official land use data (c) Land Vorarlberg;

OSM: Open Database License v1.0; CLC: Umweltbundesamt GmbH - data.umweltbundesamt.at 
Table 5. Accuracy assessment for LULC classification.

\begin{tabular}{cccccc}
\hline & \multicolumn{2}{c}{ LiDAR Data } & & \multicolumn{2}{c}{ Orthophotos } \\
\cline { 2 - 3 } \cline { 5 - 6 } & Correctness & Completeness & & Correctness & Completeness \\
\hline River & $100.00 \%$ & $99.34 \%$ & & $100.00 \%$ & $100.00 \%$ \\
Crop/Grass & $94.22 \%$ & $88.89 \%$ & & $96.15 \%$ & $70.64 \%$ \\
Forest & $90.22 \%$ & $86.94 \%$ & & $89.29 \%$ & $88.24 \%$ \\
Shrub & $50.44 \%$ & $75.67 \%$ & & $70.08 \%$ & $87.91 \%$ \\
Building & $77.33 \%$ & $60.95 \%$ & & $79.37 \%$ & $76.40 \%$ \\
Road & $83.78 \%$ & $87.27 \%$ & & $71.81 \%$ & $89.17 \%$ \\
Overall accuracy & \multicolumn{2}{c}{$82.67 \%$} & & \multicolumn{2}{c}{$83.17 \%$} \\
Average accuracy & $83.99 \%$ & & & $85.39 \%$ \\
Quality & $70.45 \%$ & $72.40 \%$ \\
Kappa & 0.9253 & & 0.9124 \\
\hline
\end{tabular}

The last roughness map based on official data is shown in Figure 3d. The dataset is the oldest one, based primarily on orthophotos from 2001/2002. The official land use is not as detailed as the formerly mentioned land uses, e.g., the paths on top of the dykes are missing and the shrub class is not captured. Yet, forest and crop/grass are available and the data is applicable to the roughness of the floodplain area.

The maps based on freely available data using CLC (Figure 3e) and OSM data (Figure 3f) show coarser LULC data than the other ones. There are no data gaps in the CLC data; yet, any details are missing (e.g., buildings). In comparison, Figure $3 \mathrm{f}$ shows a detailed map but also areas without any objects mapped. As mentioned before, this "no data" class also has an allocated roughness value. Further, the OSM data is the latest one. Users are able to edit at any time so that the data is permanently improved.

A city consists of various types of buildings. Details like pathways below buildings could be included in a 2D HN-model and improve the results. In this study, such pathways as well as the sewage system and groundwater processes are not included. Six different roughness maps are used for 2D hydrodynamic simulations; thus, some details are missing and not every map contains all roughness classes. In addition, a combination of datasets should be considered (see [49]).

\subsection{Water Depth and Flood Intensity}

Hydrodynamic simulations generate results, which are visible in water depth and flow velocity. The analyses are done for inundation area and water depth in combination with flood intensity. In Figure 4, the development of the inundation area according to the roughness layers are depicted. In addition to this, Figure 5 shows the extent of the inundation areas and the water depth. Finally, Figure 6 illustrates the distribution of flood intensity in combination with inundation area.

The HN-model simulates a flood over a timespan of six hours $(21,600 \mathrm{~s})$. At a certain point, the maximum water amount is reached and the backflow starts. This point represents the maximal stage of inundated area for each simulation and is shown in Figure 4. Thereafter, the time step of the peak is similar except for the orthophoto and LiDAR (nDSM, signal intensity) roughness data. However, at $11,400 \mathrm{~s}$, all models reach a peak extent of water, which is used for a comparison. Further, Figure 4 
indicates that the inundation area from the models based on roughness derived from orthophoto and official land use data is smaller than the other ones.

Figure 4. Development of the inundation area with time steps (s).

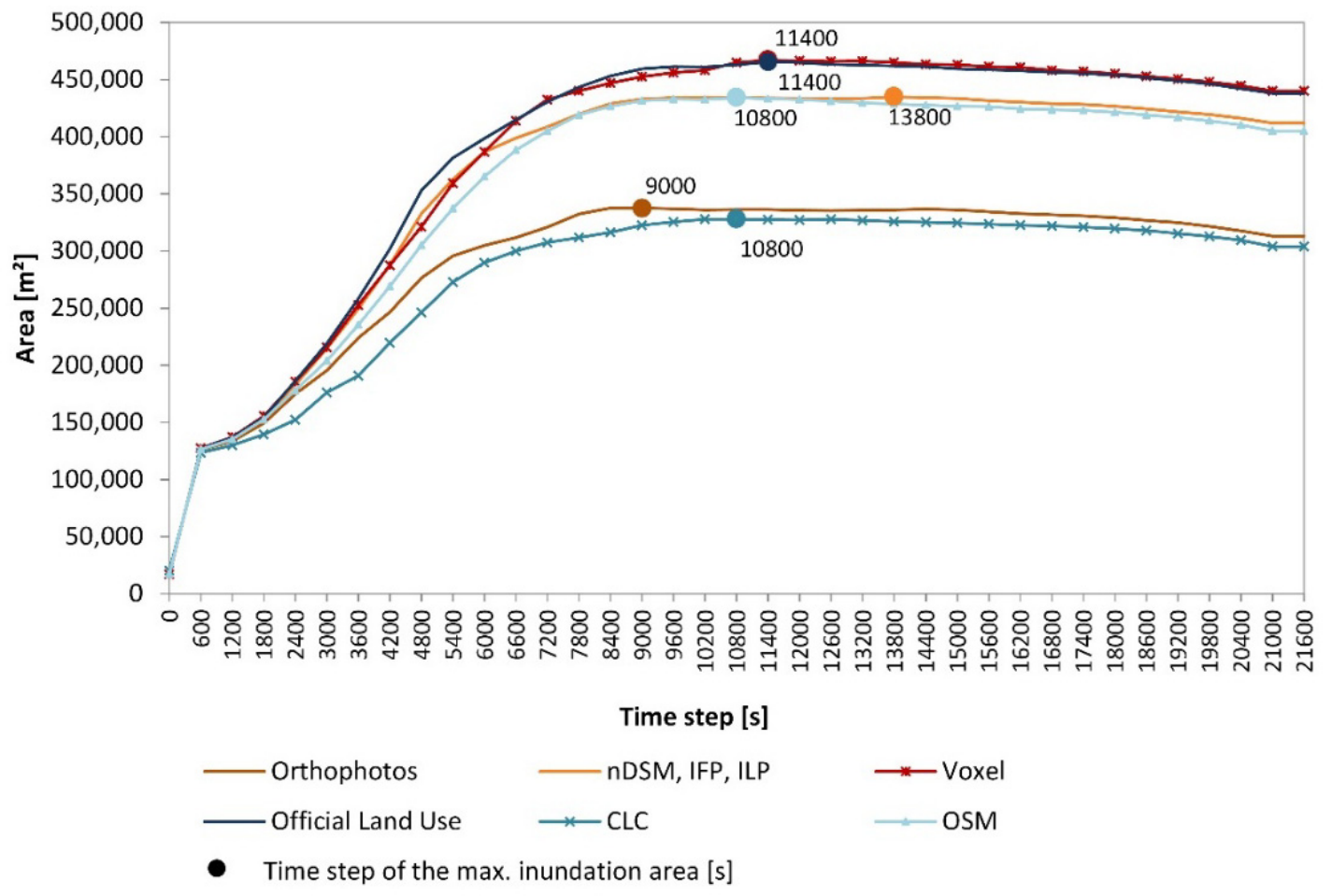

Orthophotos, LiDAR data, official land use (C) Land Vorarlberg; OSM: Open Database License v1.0; CLC: Umweltbundesamt $\mathrm{GmbH}$ - data.umweltbundesamt.at

Figure 5 shows the water depth and inundated area after a simulation time of 11,400 s. There are three noticeable inundation areas for all hydrodynamic simulations. Firstly, in the Southeast directly after the mouth of a canal in the Bregenzer Ache; secondly, in the center of the study area, right before a bridge linking Bregenz in the eastern part and Hard in the western part; thirdly, the flooded areas located after the bridge on both river sides in the Northwest of the study area. Thus, in Bregenz, there is a housing area by the river in the North of the study area the so-called "Achsiedlung" and in Hard; there we can find a forest affected by the flood.

In Figure 5a the result of the simulation with the roughness map based on orthophotos is depicted and a small inundation area is visible. In comparison to the other ones, the flooded area in front of the bridge in the middle of the study area is very small. A reason for this might be that a lot of shrub in the bank area was classified there. This assumption cannot be verified because in the voxel approach there is also a lot of shrub but more flooding. Concerning water depth, the river itself is the deepest area. Further, one dark blue location in the Achsiedlung is visible. An artificial terrain depression was built there because of underground parking lots and the dyke. This place is filled with water up to more than two meters in all simulations. If underground parking lots and pathways below the buildings were inserted, the water depth would be lower. However, the model based on orthophotos does not realistically simulate the flood. 
Figure 5. Results of the flood simulation at time step 11,400 s with water depth in meter based on the roughness derivation with (a) orthophotos; (b) nDSM, IFP, ILP; (c) voxel; (d) official land use data; (e) CLC data; (f) OSM data.
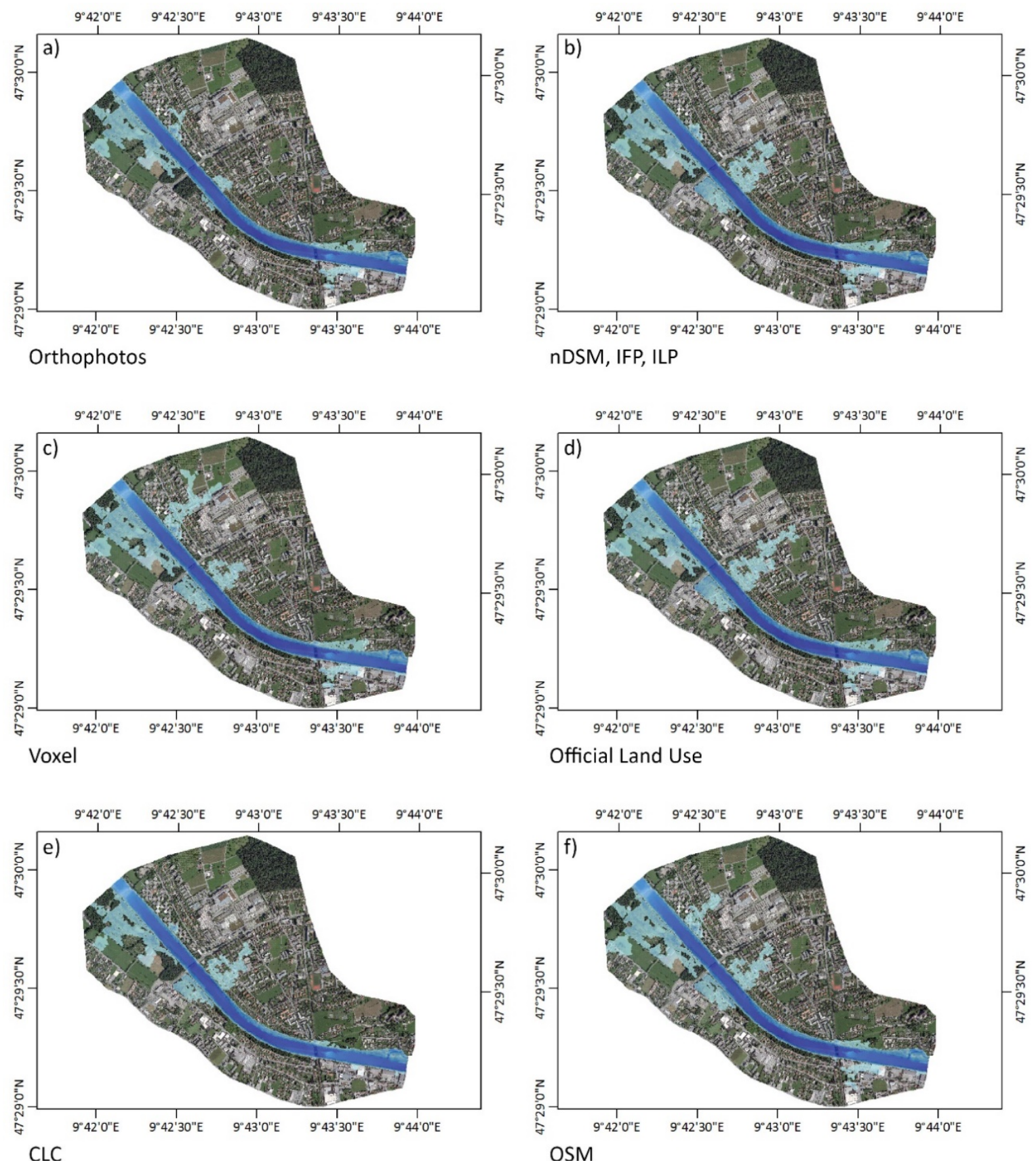

Depth in Meter

Time Step: 11400 s
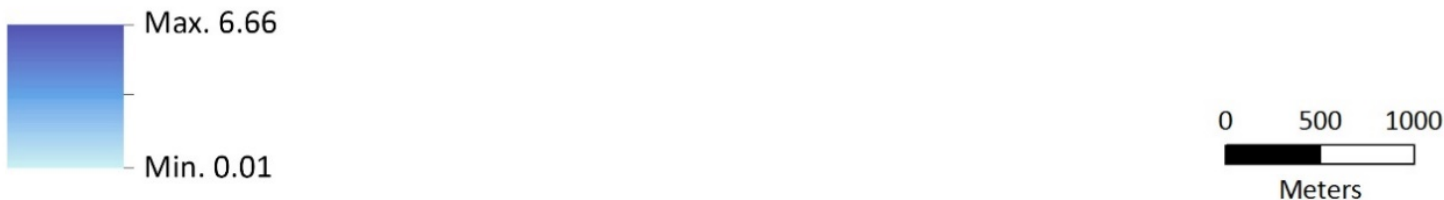

Orthophotos, LiDAR data, official land use (c) Land Vorarlberg:

OSM: Open Database License v1.0; CLC: Umweltbundesamt GmbH - data.umweltbundesamt.at 
Figure 6. Flood intensity with water depth (m) as impact parameter.

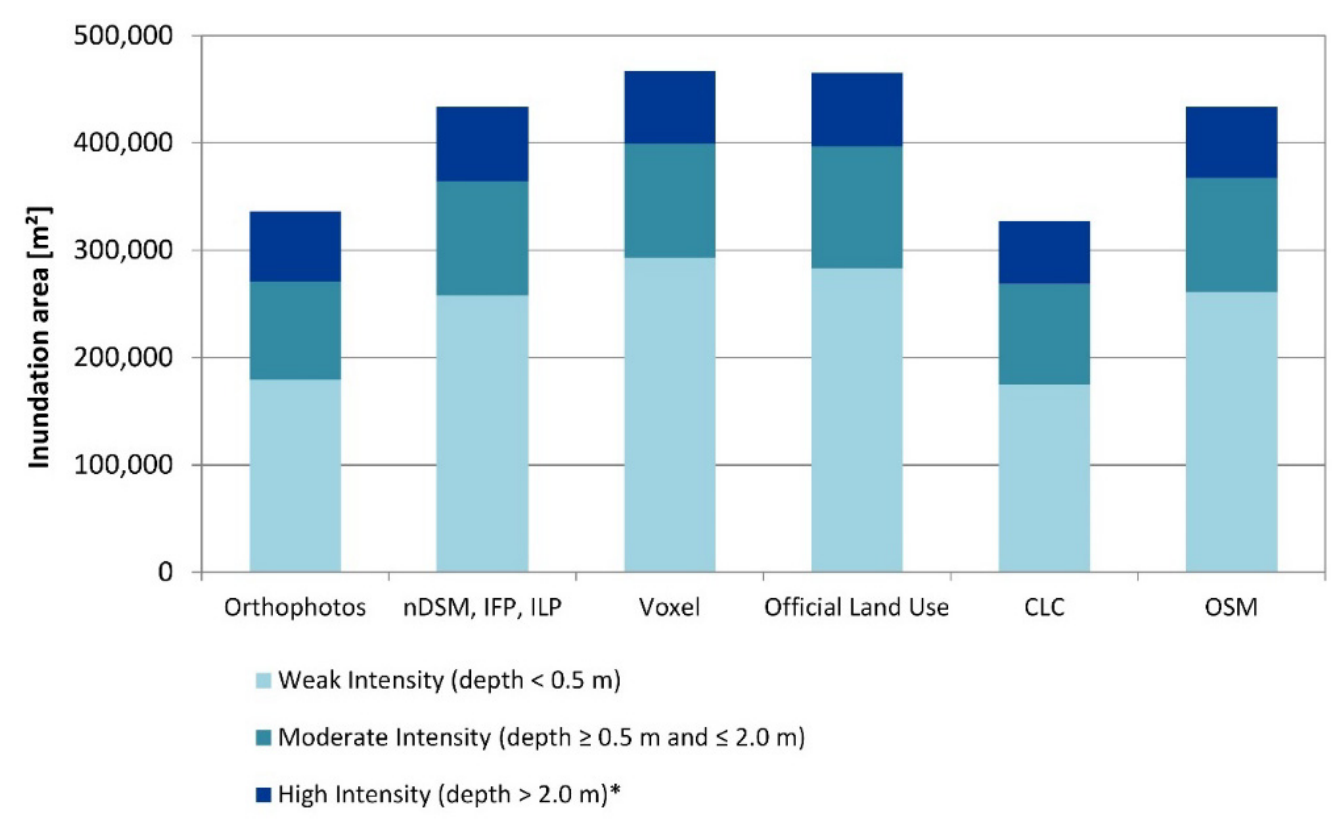

Orthophotos, LiDAR data, official land use (c) Land Vorarlberg;

OSM: Open Database License v1.0; CLC: Umweltbundesamt GmbH - data.umweltbundesamt.at _ * minus river bed area

The simulation using nDSM and signal intensity data roughness map (Figure 5b) is more suitable. The inundation areas on both river sides next to the bridge are larger than in Figure 5a. Further, on the left river side the water depth is higher in all simulation results apart from Figure 5a. Many buildings are affected on the east river side. The simulation results based on nDSM and signal intensity information offer a suitable way to estimate the spatial impact of a flood.

Another roughness map based on LiDAR data derived by the voxel-based approach (Figure 5c) shows a large inundation in the Achsiedlung but a smaller one in front of the bridge. In the results gained with official land use data (Figure 5d), a large inundation area in the center of the study area as well as in the North Western area is depicted.

The models with roughness maps based on freely available data (Figure 5e,f) lead to different flooded areas. The inundated area by using CLC data for the roughness map calculation is very small in comparison to the other one (Figure 4). The roughness map is too coarse in the study area. More realistic results are gained with OSM data as illustrated in Figure $5 \mathrm{f}$. The inundation areas are similar to Figure $5 b$ and only small deviations especially in the Achsiedlung are visible. However, the areas without any objects mapped can be considered as disadvantage. In this study area, it was possible to choose an appropriate roughness value for these areas but further research is required in order to confirm the results.

In Figure 6 the flood intensities with water depth as impact parameter are depicted. The values reflect the total area value of inundated regions in square meters. The deepest regions regarding elevation are in between the dykes and therefore the river bed area is subtracted from the total area values. This illustration confirms former descriptions. Simulations based on orthophotos or CLC data lead to smaller area values of inundated regions, while the other values are similar to each other. Regarding the entire inundated areas $\left(\mathrm{m}^{2}\right)$, the largest inundation area has $30 \%$ more flooded area than the smallest inundation area. The values of inundated areas are similar, however, the locations where 
the inundation takes place differ due to the different roughness values close to the river course (Figures 3 and 5).

The results of using $\mathrm{nDSM}$ and OSM are very alike regarding to the division to the flood intensity classes. In contrast, the values of inundation area with weak flood intensity in the voxel and official land use data simulations are larger. Seventy-five up to 189 buildings are potentially affected by the flood. However, only up to two buildings are threatened by high flood intensity. These numbers in combination with the affected area give a hint with regard to risk estimation. Further data is required for a risk assessment on microscale or mesoscale by using methods e.g., of Maiwald and Schwarz [28] or Thieken [25].

\section{Conclusions}

Floods are recurring natural disasters and therefore flood protection is needed. Flood simulations help to make decisions to improve flood protection measures by visualizing affected areas. The aim of this study was to simulate floods based on different roughness maps. The simulations used various roughness maps, which are derived with different methods. The results differ in inundation area, water depth and flood intensity. The analysis revealed that the simulation results with roughness maps based on orthophotos and CLC data with maximum inundation areas less than $337,578 \mathrm{~m}^{2}$ were lower by a factor of 1.29 compared to the other four roughness maps which resemble each other with maximum simulated inundation areas between 434,186 $\mathrm{m}^{2}$ and 466,961 $\mathrm{m}^{2}$. The OSM data is not complete and thus it is not entirely applicable to every study area. Therefore, the assessment of the OSM data quality is essential. However, in most areas regularly updated crowdsourced data is available depending on the activity of the community [51]. Moreover, further research is required for using LiDAR data (e.g., fusion with additional image data, combined approach using signal intensity, nDSM and voxel). The study revealed that there is no visible effect of shrub on the water flow but theoretically there is a remarkable influence. A combination of the voxel and $\mathrm{nDSM} /$ signal intensity for deriving roughness maps in a different study area could help to investigate possible influences.

In conclusion, the study shows that the commonly used orthophotos and CLC data were not the best solution for a roughness parameterization in this analysis. Regarding CLC data the spatial resolution for small test sites such as the one used in this study is too coarse. In contrast, LiDAR data and OSM data gained reasonable results. Using LiDAR data for the roughness map derivation can solve occurring data fusion problems, because LiDAR data is also used to derive the geometry for HN-models. Depending on the study area LiDAR data might not be up-to-date. Thus, using OSM data for roughness maps is beneficial in areas with high OSM data quality, because the contributors are able to update the dataset regularly.

An appropriate roughness map considering the study area should be chosen for estimating consequences of floods as natural disasters. Therefore, LiDAR and OSM data should be taken into account. It is important to keep the data base up to date in order to enable realistic flood predictions. Prevention measures can be planned on basis of flood simulations and reduce the impact on residents. Further, existing flood protection has to be constantly checked, e.g., by using hydrodynamic-numerical models, and improvements can be carried out accordingly. 


\section{Acknowledgments}

The authors want to express their gratitude to the Federal State Vorarlberg (Austria) for the possibility to use their geodata. We would also like to acknowledge the financial support from the Austrian Science Funds (FWF) as part of the Vienna Doctoral Programme on Water Resource Systems (DK-plus W1219-N22) and the financial support by the German Research Foundation (DFG) and the Heidelberg University within the funding programme Open Access Publishing.

\section{Author Contributions}

Helen Dorn developed and implemented the research design and performed data processing and analysis, executed the manuscript writing and coordinated the paper revisions. Michael Vetter performed the input data preparation and execution of the hydrodynamic simulation, and he carried out the LiDAR voxel-based roughness derivation. Bernhard Höfle proposed the overall research idea and contributed to the workflow implementation and manuscript compilation and revisions.

\section{Conflicts of Interest}

The authors declare no conflict of interest.

\section{References}

1. CRED EM-DAT: The International Disaster Database: Natural Disaster Trends. Available online: http://www.emdat.be/natural-disasters-trends (accessed on 30 September 2013).

2. Pasche, E. The New EU-Flood Policy and Its Consequences for Urban Flood Management. In Special Aspects of Urban Flood Management: Proceedings of Cost Session Aquaterra Conference 2007; Pasche, E., Ed.; COST Office: Hamburg, Germany, 2008; pp. 137-160.

3. Berchtold, M. Lebensader Bregenzerach—von Schoppernau nach Egg: Phase I Bestandsaufnahme. Available online: http://www.vorarlberg.at/pdf/bregenzerach_bestandserh.pdf (accessed on 30 September 2013).

4. Amt der Vlbg. Landesreg. Das Starkregen- und Hochwasserereignis des August 2005 in Vorarlberg: Ein Bericht des Amtes der Vorarlberger Landesregierung. Available online: http://www.vorarlberg.at/pdf/naturereignisdokumentatio.pdf (accessed on 1 May 2013).

5. Straatsma, M.W.; Baptist, M.J. Floodplain roughness parameterization using airborne laser scanning and spectral remote sensing. Remote Sens. Environ. 2008, 112, 1062-1080.

6. Straatsma, M.; Huthoff, F. Uncertainty in 2D hydrodynamic models from errors in roughness parameterization based on aerial images. Phys. Chem. Earth Parts $A / B / C$ 2011, 36, 324-334.

7. Wagner, W.; Vetter, M.; Bartsch, A. Novel Microwave- and Lidar Remote Sensing Techniques for Monitoring of In-Land Water Resources. In Acatech Materialien Nr. 7: Munich, Germany, 2011; pp.1-42.

8. Mandlburger, G.; Hauer, C.; Höfle, B.; Habersack, H.; Pfeifer, N. Optimisation of LiDAR derived terrain models for river flow modelling. Hydrol. Earth Syst. Sci. 2009, 13, 1453-1466. 
9. Vetter, M.; Höfle, B.; Hollaus, M.; Gschöpf, C.; Mandlburger, G.; Pfeifer, N.; Wagner, W. Vertical vegetation structure analysis and hydraulic roughness determination using dense ALS point cloud data-A voxel based approach. Int. Arch. Photogramm. Remote Sens. Spat. Inf. Sci. 2011, 38, Part 5/W 12, 265-270.

10. Merkel, U.; Kron, A.; Oberle, P. Combined 1- and 2-Dimensional Numerical Modelling Techniques for Operational Flood Simulation in Complex River Systems: Case Study "Middle Elbe". In Special Aspects of Urban Flood Management, Proceedings of Cost Session Aquaterra Conference; Pasche, E., Ed.; COST Office: Hamburg, Germany, 2008; pp. 241-264.

11. Oberle, P. Integrales Hochwassersimulationssystem Neckar: Verfahren, Werkzeuge, Anwendungen und Übertragung; Universität Fridericiana zu Karlsruhe (TH): Karlsruhe, Germany, 2004.

12. Vetsch, D.; Rousselot, P.; Fäh, R. Flussgebietsmodellierung mit der Simulationssoftware BASEMENT. Wasser Energie Luft 2011, 103, 313-319.

13. Lane, S.N.; Bradbrook, K.F.; Richards, K.S.; Biron, P.A.; Roy, A.G. The application of computational fluid dynamics to natural river channels: Three-dimensional versus two-dimensional approaches. Geomorphology 1999, 29, 1-20.

14. Chow, V.T. Open-Channel Hydraulics, Reprint, 1959; Blackburn Press: Caldwell, NJ, USA, 2009.

15. Medeiros, S.C.; Hagen, S.C.; Weishampel, J.F. Comparison of floodplain surface roughness parameters derived from land cover data and field measurements. J. Hydrol. 2012, 452-453, 139-149.

16. Doncker, L.; Troch, P.; Verhoeven, R.; Bal, K.; Meire, P.; Quintelier, J. Determination of the manning roughness coefficient influenced by vegetation in the river Aa and Biebrza river. Environ. Fluid Mech. 2009, 9, 549-567.

17. Lumbroso, D.; Gaume, E. Reducing the uncertainty in indirect estimates of extreme flash flood discharges. J. Hydrol. 2012, 414-415, 16-30.

18. Arcement, G.J.; Schneider, V.R. Guide for Selecting Manning's Roughness Coefficients for Natural Channels and Flood Plains; US Government Printing Office: Washington, DC, USA, 1989.

19. Mandlburger, G. Topographische Modelle für Anwendungen in Hydraulik und Hydrologie. Ph.D. Thesis, Technische Universität Wien, Vienna, October 2006.

20. Bates, P.D.; Horritt, M.S.; Smith, C.N.; Mason, D. Integrating remote sensing observations of flood hydrology and hydraulic modelling. Hydrol. Process 1997, 11, 1777-1795.

21. Mason, D.C.; Cobby, D.M.; Horritt, M.S.; Bates, P.D. Floodplain friction parameterization in two-dimensional river flood models using vegetation heights derived from airborne scanning laser altimetry. Hydrol. Process. 2003, 17, 1711-1732.

22. Thieken, A.H.; Kreibich, H.; Müller, M.; Merz, B. Coping with floods: Preparedness, response and recovery of flood-affected residents in Germany in 2002. Hydrol. Sci. J. 2007, 52, 1016-1037.

23. Büchele, B.; Kreibich, H.; Kron, A.; Thieken, A.; Ihringer, J.; Oberle, P.; Merz, B.; Nestmann, F. Flood-risk mapping: Contributions towards an enhanced assessment of extreme events and associated risks. Nat. Hazards Earth Syst. Sci. 2006, 6, 485-503.

24. Thieken, A.H. Hochwasserschutz in Deutschland: Neue modelle zur abschätzung von hochwasserschäden. Ökologisches Wirtschaften 2008, 3, 30-34. 
25. Thieken, A.H.; Ackermann, V.; Elmer, F.; Kreibich, H.; Kuhlmann, B.; Kunert, U.; Maiwald, H.; Merz, B.; Müller, M.; Piroth, K.; et al. Methods for the Evaluation of Direct and Indirect Flood Losses. In Proceedings of the 4th International Symposium on Flood Defence: Managing Flood Risk, Reliability and Vulnerability, Toronto, ON, Canada, 6-8 May 2008.

26. Egli, T.E. Hochwasserschutz und Raumplanung: Schutz vor Naturgefahren mit Instrumenten der Raumplanung, dargestellt am Beispiel von Hochwasser und Murgängen; Vdf, Hochsch.-Verl. an der ETH: Zürich, Switzerland, 1996; Volume 100.

27. Schwarz, J.; Maiwald, H.; Gerstberger, A. Quantifizierung der Schäden infolge Hochwassereinwirkung: Fallstudie Eilenburg. Bautechnik 2005, 82, 845-856.

28. Maiwald, H.; Schwarz, J. Ermittlung von Hochwasserschäden unter Berücksichtigung der Bauwerksverletzbarkeit: EDAC-Hochwasserschadensmodell. Zentrum für die Ingenieuranalyse von Erdbebenschäden: Scientific technical reports 01; Verlag der Bauhaus-Universität Weimar: Weimar, Germany, 2011.

29. Bundesamt für Umwelt Schweiz. Hilfe-Assistent zum Excel-Tool Methode BWG für die Abschätzung des Schadenpotentials: Überschwemmung und Übermurung. Available online: http://www.bafu.admin.ch/dokumentation/03393/03517/index.html?lang=de (accessed on 12 March 2013).

30. Godina, R.; Holzmann, H.; Lehmann, T.; Formayer, H.; Haas, P. Floodrisk II: Vertiefung und Vernetzung zukunftsweisender Umsetzungsstrategien zum integrierten Hochwasserschutz. Available online: https://imp.boku.ac.at/klima/literatur/FRII_Endbericht_final.pdf (accessed on 13 March 2013).

31. Land Vorarlberg. Abflussmessstationen in Vorarlberg: Messstation Kennelbach. Available online: http://www.vorarlberg.at/abfluss/ (accessed on 13 March 2013).

32. Amt der Vlbg. Landesreg. Abt. Wasserwirtschaft. Nationaler Gewässerbewirtschaftungsplan 2009: Bregenzerach: Maßnahmenkonzept. 2010. Available online: http://www.vorarlberg.at/pdf/ ngp_bregenzerach.pdf (accessed on 19 March 2013).

33. Landesvermessungsamt Feldkirch. Orthofotomosaik Vorarlberg 2009; 2010.

34. TopScan GmbH. Projektbericht bezüglich der Laserscannermessung Unterland und Vorderwald im Auftrag des Landesvermessungsamtes Feldkirch; TopScan GmbH: Rheine, German, 2006.

35. Höfle, B.; Pfeifer, N. Correction of laser scanning intensity data: Data and model-driven approaches. ISPRS J. Photogramm. Remote Sens. 2007, 62, 415-433.

36. Jäger, F. Landnutzungsklassifizierung aus hochauflösenden Orthofotos Land Vorarlberg 2001/02: Technischer Bericht; GeoVille Informationssysteme:Innsbruck, Austria, 2007.

37. Umweltbundesamt GmbH. CORINE Land Cover. Available online: http://www.umweltbundesamt.at/umwelt/raumordnung/flaechennutzung/corine/ (accessed on 5 March 2013).

38. Resch, B. People as Sensors and Collective Sensing-Contextual Observations Complementing Geo-Sensor Network Measurements. In Progress in Location-Based Services; Krisp, J.M., Ed.; Springer: Berlin/Heidelberg, Germany, 2013; pp. 391-406.

39. Lechner, M. Nutzungspotentiale Crowdsource-Erhobener Geodaten auf Verschiedenen Skalen. Ph.D. Thesis, Albert-Ludwigs-Universität, Freiburg im Breisgau, Germany, September 2011. 
40. Vetter, M.; Höfle, B.; Mandlburger, G.; Rutzinger, M. Estimating changes of riverine landscapes and riverbeds by using airborne LiDAR data and river cross-sections. Zeitschrift für Geomorphologie 2011, 55, 51-65.

41. Visual Learning Systems. Feature Analyst 4.2 for ArcGIS: Reference Manual; Visual Learning Systems, Inc.: Missoula, MT, USA, 2001-2008.

42. Heipke, C.; Mayer, H.; Wiedemann, C.; Jamet, O. Evaluation of automatic road extraction. Int. Arch. Photogramm. Remote Sens. Spat. Inf. Sci. 1997, 32, Part 3-2W2, 47-56.

43. Arie, B.-D. Comparison of classification accuracy using Cohen's Weighted Kappa. Expert Syst. Appl. 2008, 34, 825-832.

44. Lowry, R. VasserStats: Kappa. Available online: http://vassarstats.net/kappa.html (accessed on 16 March 2013).

45. Bechteler, W.; Nujić, M.; Patt, H.; Vogel, G. Hydraulische und Wasserbauliche Grundlagen. In Hochwasser-Handbuch: Auswirkungen und Schutz; Patt, H., Ed.; Springer: Berlin/Heidelberg, Germany, 2001; pp. 59-168.

46. Volz, C.; Rousselot, P.; Vetsch, D.; Müller, R.; Fäh, R. Dual-Mesh Ansatz zur Numerischen Simulation von Sedimenttransport auf Unstrukturierten Berechnungsgittern. In Wasserbau in Bewegung... von der Statik zur Dynamik: Beiträge zum 15. Gemeinschafts-Symposium der Wasserbau-Institute TU München, TU Graz und ETH Zürich: Vom 1. bis 3. Juli 2010 in Wallgau, Oberbayem; Rutschmann, P., Ed.; Technische Universität München: Munich, Germany, 2010; pp. 203-212.

47. Fäh, R.; Mueller, R.; Rousselot, P.; Vetsch, D.; Volz, C.; Vonwiller, L.; Veprek, R.; Farshi, D. System Manuals of BASEMENT: Version 2.2; Labratory of Hydraulics, Glaciology and Hydrology (VAW), ETH Zürich: Zurich, Switzerland, 2011.

48. Syme, W.J. Flooding In Urban Areas-2D Modelling Approaches for Buildings and Fences. In Proceedings of the Engineers Australia, 9th National Conference on Hydraulics in Water Engineering, Darwin, NT, Australia, 23-26 September 2008.

49. Wang, J.; Zeng, C.; Lehrbass, B. Building Extraction from LiDAR and Aerial Images and Its Accuracy Evaluation. In Proceedings of the 2012 IEEE International Geoscience and Remote Sensing Symposium (IGARSS), Munich, Germany, 22-27 July 2012; pp. 64-67.

50. Vetter, M. Airborne Laser Scanning Terrain and Land Cover Models as Basis for Hydrological and Hydraulic Studies. Centre for Water Resource Systems, Technische Universität Wien, Vienna, Austria, 2013.

51. Neis, P.; Zielstra, D.; Zipf, A. Comparison of volunteered geographic information data contributions and community development for selected world regions. Future Internet 2013, 5, 282-300.

(C) 2014 by the authors; licensee MDPI, Basel, Switzerland. This article is an open access article distributed under the terms and conditions of the Creative Commons Attribution license (http://creativecommons.org/licenses/by/3.0/). 